\title{
Forecast predictions for the COVID-19 pandemic in Brazil by statistical modeling using the Weibull distribution for daily new cases and deaths
}

Vitor Hugo Moreau ( $\square$ vitorhmc@ufba.br)

Fedral University of Bahia https://orcid.org/0000-0002-5393-0645

\section{Research Article}

Keywords: COVID-19, Forecast prediction, Statistical modeling, Weibull

Posted Date: June 9th, 2020

DOI: https://doi.org/10.21203/rs.3.rs-34092/v1

License: (c) (i) This work is licensed under a Creative Commons Attribution 4.0 International License.

Read Full License

Version of Record: A version of this preprint was published at Brazilian Journal of Microbiology on August 27th, 2020. See the published version at https://doi.org/10.1007/s42770-020-00331-z. 


\section{Brazilian Journal of Microbiology}

\section{Forecast predictions for the COVID-19 pandemic in Brazil by statistical modeling using the Weibull distribution for daily new cases and deaths

\author{
--Manuscript Draft--
}

\begin{tabular}{|c|c|}
\hline Manuscript Number: & BJMI-D-20-00486 \\
\hline Full Title: & $\begin{array}{l}\text { Forecast predictions for the COVID-19 pandemic in Brazil by statistical modeling using } \\
\text { the Weibull distribution for daily new cases and deaths }\end{array}$ \\
\hline Section/Category: & Clinical Microbiology \\
\hline Abstract: & $\begin{array}{l}\text { COVID-19 has killed more than } 330.000 \text { people worldwide and more than } 21,000 \\
\text { Brazilians. Since there are no specific drugs or vaccines, the available tools against } \\
\text { COVID-19 are preventive, such as the use of personal protective equipment, social } \\
\text { distancing, lockdowns and mass testing. Such measures are hindered in Brazil due to } \\
\text { a restrict budget, low educational level of the population and misleading attitudes from } \\
\text { the federal authorities. Predictions for COVID-19 are of pivotal importance to subsidize } \\
\text { and mobilize health authorities' efforts in applying the necessary preventive strategies. } \\
\text { The Weibull distribution was used to model the forecast prediction of COVID-19, in four } \\
\text { scenarios, based on the curve of daily new deaths as a function of time. The date in } \\
\text { which the number of daily new deaths will fall below the rate of } 3 \text { deaths per million, the } \\
\text { mean level considered by some countries to relax stay-at-home measures, was } \\
\text { estimated. If the daily new deaths curve was bended today (i. e. about } 1,250 \text { deaths } \\
\text { per day), the predicted date would be on June } 18 \text { th . Analysis of the lethality rate } \\
\text { allowed the estimation of daily new cases and total death toll at the end of the } \\
\text { outbreak. Our results suggest that each additional day that lasts to bend the daily new } \\
\text { deaths curve can correspond to additional } 3,718 \text { deaths at the end of COVID-19 } \\
\text { outbreak in Brazil (R } 2=0.9938 \text { ). Predictions of the outbreak can be used to guide } \\
\text { Brazilian health authorities in the decision making to properly fight COVID-19 } \\
\text { pandemic. }\end{array}$ \\
\hline Corresponding Author: & $\begin{array}{l}\text { Vitor Hugo Moreau, PhD } \\
\text { Universidade Federal da Bahia Instituto de Ciencias da Saude } \\
\text { Salvador, Brazil BRAZIL }\end{array}$ \\
\hline First Author: & Vitor Hugo Moreau, PhD \\
\hline \multicolumn{2}{|l|}{ First Author Secondary Information: } \\
\hline Order of Authors: & Vitor Hugo Moreau, PhD \\
\hline \multicolumn{2}{|c|}{ Order of Authors Secondary Information: } \\
\hline Author Comments: & $\begin{array}{l}\text { Dear Sirs(Madams) } \\
\text { The Original MS attached to this submission brings results based on epidemiological } \\
\text { data from COVID-19 outbreak in Brazil. Such results gain special meaning if published } \\
\text { as soon as possible. I ask you, if possible, to accelerate the revision process. } \\
\text { Thank you and best regards. }\end{array}$ \\
\hline
\end{tabular}


TITLE: Forecast predictions for the COVID-19 pandemic in Brazil by statistical modeling using the Weibull distribution for daily new cases and deaths

AUTHOR: Vitor Hugo Moreau, Ph.D.

E-MAIL: vitorhmc@ufba.br

ORCID: 0000-0002-5393-0645

AFFILIATION: Department of Biotechnology - DBTEC

Institute of Health Sciences - ICS

Federal University of Bahia - UFBA

\section{Acknowledgment}

To Dr. Ricardo Portela for the critical reading of the manuscript.

To Dr. Gilson Carvalho for valuable discussions of the theme. 


\begin{abstract}
COVID-19 has killed more than 330.000 people worldwide and more than 21,000 Brazilians. Since there are no specific drugs or vaccines, the available tools against COVID-19 are preventive, such as the use of personal protective equipment, social distancing, lockdowns and mass testing. Such measures are hindered in Brazil due to a restrict budget, low educational level of the population and misleading attitudes from the federal authorities. Predictions for COVID-19 are of pivotal importance to subsidize and mobilize health authorities' efforts in applying the necessary preventive strategies. The Weibull distribution was used to model the forecast prediction of COVID-19, in four scenarios, based on the curve of daily new deaths as a function of time. The date in which the number of daily new deaths will fall below the rate of 3 deaths per million, the mean level considered by some countries to relax stay-at-home measures, was estimated. If the daily new deaths curve was bended today (i. e. about 1,250 deaths per day), the predicted date would be on June $18^{\text {th }}$. Analysis of the lethality rate allowed the estimation of daily new cases and total death toll at the end of the outbreak. Our results suggest that each additional day that lasts to bend the daily new deaths curve can correspond to additional 3,718 deaths at the end of COVID-19 outbreak in Brazil $\left(\mathrm{R}^{2}=0.9938\right)$. Predictions of the outbreak can be used to guide Brazilian health authorities in the decision making to properly fight COVID-19 pandemic.
\end{abstract}

Keywords: COVID-19, Forecast predictions, Weibull distribution, Brazil, Death toll 


\section{Funding}

This work was supported by author's own resources.

\section{Conflicts of interest/Competing interests}

The author declares no financial interests or connections, direct or indirect, or other situations that might raise the question of bias in the work reported or the conclusions.

\section{Ethics approval}

Not applicable

\section{Consent to participate}

Not applicable. VHM is the only author of this MS.

\section{Consent for publication}

Not applicable. VHM is the only author of this MS.

\section{Availability of data and material}

Not applicable.

\section{Code availability}

Not applicable.

\section{Authors' contributions}

The Author has gained full consent from the responsible authorities at the institute/organization where the work has been carried out. 


\section{Introduction}

Since the World Health Organization declared the COVID-19 outbreak a Public Health Emergency of International Concern, in January $30^{\text {th }} 2020$, more than 4.5 million cases of the disease and 330.000 deaths related with the infection with SARS-CoV2 virus were registered worldwide. The impacts of COVID-19 in lowand middle- income countries (LMICs) are of great concern [1,2], since in these countries a large percentage of the population live in overcrowded conditions, with deficient access to clean water and sanitizers, among other factors that limit people living in LMICs to follow the public health advices on how to reduce the spread of the virus [3]. Although Brazil has the ninth larger Gross Domestic Product [4], $42 \%$ of the Brazilian population live with less than 10 USD per day and more than ten million Brazilians live in extreme poverty [5]. As in other countries, poverty and social inequality are being aggravated by the COVID-19 pandemic in Brazil. Brazil occupies now the second place in number of registered COVID-19 cases [6]. Forecast predictions made by the Imperial College (London, UK) present Brazil as the country with the highest rate of transmission and one of the countries from where a large number of deaths are expected in the next weeks [7]. The health crisis is sharpened by a political crisis, depicted by a second change of Health Minister in less than one month, [8], and Federal government authorities constantly denying the severity of COVID-19 pandemic and the scientific consensus on the lockdown and social distancing measures [9].

Forecast predictions configure a pivotal strategy for decision making in the evaluation of measures against COVID-19 $[10,13]$ and should be closely considered by governments and health authorities. In this work, we have used the Weibull distribution on the number of daily new cases and deaths of COVID-19 data to predict the evolution of pandemic [14]. The Weibull distribution is one of the most commonly used parametric lifetime models [15], mostly for its parsimony, its ability to satisfactorily model data which are commonly encountered in survival analysis and its availability in statistical software packages $[15,16]$. A parameter called DiagnosticDeath lag (DDlag), that strongly correlates with lethality rate (LR), was calculated using as a base the Brazil's official data. DDlag can be used to predict COVID-19 evolution and to evaluates the LR, as well as to infer the level of underreported cases [14]. We took in account four distinct scenarios based in the daily number of new deaths, considering the maximum of 1,250,1,500,1,750 and 2,000 daily new deaths at the peak top of the curve. Because our predictions are based in the number of daily new deaths, it can be daily reviewed with the objective to evaluate the measures further taken to fight the COVID-19 pandemic in Brazil, such as lockdowns and mass testing, and also when these measures should be reformulated. 


\section{Material and Methods}

Data on Brazil's daily and total number of confirmed cases and deaths were obtained from the Our World in Data Project [6] as comma-spaced values (CSV) files, processed in MS Excel 2019 and exported to Sigma Plot 14.0 with the objective to build scatter and regression plots. Data fitting was performed through Sigma Plot using the Dynamic Fit Wizard Tool and the Weibull 4-parameter integrated to the software, described as:

$f(\tau)=\left\{\begin{array}{cl}0 & , \quad \tau \leq \tau_{0}-\delta\left(\frac{\gamma-1}{\gamma}\right)^{\frac{1}{\gamma}} \\ a\left(\frac{\gamma-1}{\gamma}\right)^{\frac{1-\gamma}{\gamma}}\left|\frac{\tau-\tau_{0}}{\delta}+\left(\frac{\gamma-1}{\gamma}\right)^{\frac{1}{\gamma}}\right|^{\gamma-1} e^{-\left|\frac{\tau-\tau_{0}}{\delta}+\left(\frac{\gamma-1}{\gamma}\right)^{\frac{1}{\gamma}}\right|^{\gamma}+\left(\frac{\gamma-1}{\gamma}\right)}, & \text { otherwise }\end{array}\right.$

where $\tau$ is the time; $f(\tau)$ is the number of new cases or new deaths as a function of $\tau$, $\tau_{0}$ is the time where the maximum of the projected peak is observed (maximum number of daily cases or deaths, or peak top); $\alpha$ is the value of $f(\tau)$ at $\tau_{0} ; \gamma$ and $\delta$ are constants. Values of $\alpha, \tau_{0}, \gamma$, and $\delta$ were calculated in order to find the best fit to $\tau$ and $f(\tau)$ data.

The Diagnostic-Death lag (DDlag) was determined as [14]:

$\Delta \tau_{0}=\tau_{0}^{D}-\tau_{0}^{C}$

where $\Delta \tau_{0}=$ DDlag, $\tau_{0}^{C}$ is the value of $\tau$ on the inflection of the daily new cases curve and $\tau_{0}^{D}$ is the value of $\tau$ on the inflection of daily new deaths curve. The correlation between DDlag and LR was given by [14]:

DDlag $=-10 \ln \frac{L R}{0.1927}$ 
The forecast predictions in this work were made taking in account four prospective scenarios, based on the maximum number of daily new deaths for COVID-19 registered at the peak (inflection point): 1,250 death per day, as maximum - this is practically the actual scenario (May, 22) and is being considering the most optimistic possibility, and 1,500, 1,750 and 2,000 deaths per day. Data of daily new deaths for COVID-19 in Brazil were fit within the Weibull distribution (Equation 1). Calculations for each scenario were performed by fixing $\alpha$ in Equation 3.

The estimation of the safe date to relaxing lockdown measures in Brazil were done based on that observed in other countries, such as Spain, Italy, Germany and Canada, which start easing lockdown measures when the number of daily new deaths and cases dropped, in average, below 3 deaths and 20 cases per million habitants, respectively, as presented in data from Our World in Data Project [6]. In Brazil, with actual population of 209.5 million habitants, it corresponds to 628 deaths and 4,190 cases, respectively. We do not have parameters to evaluate if this number can be safely considered as a base for health measures against COVID-19 pandemics, however, purely based on the examples previously described for other countries, we used these numbers to project dates for start easing stay-at-home requirements in Brazil.

Constants' standard errors and the fit root square values were obtained in the same software. Error propagation was done as regular rules [17]. 


\section{Results}

Data analysis can be of outstanding importance during disease outbreaks, mainly if fast decision making is crucial to slow down the spread of the disease. The prediction of the course of COVID-19 pandemic in highly affected countries is considered as a live-saving demand [18, 19]. Data on cases and deaths of COVID-19 in Brazil were extracted from Our World in Data Project on Coronavirus [6]. The lethality rate (LR) for COVID-19 in Brazil was calculated using the number of cumulative deaths divided by the number of cumulative registered cases. First case in Brazil was registered on February, $26^{\text {th }}$. Since then, the LR for COVID-19 in Brazil has grown until it reaches a constant value and maintain it to the end of the outbreak, as normally observed in other countries (data not show). Figure 1 shows that percentual LR for COVID-19 in Brazil reached (7.0 \pm 0.2$) \%$. As LR tends to be constant to the end of the epidemic, this value was used to estimate the maximum number of daily new cases at the peak of the COVID-19 epidemic curve from the number of daily new deaths chosen for each scenario (see Material and Methods). The number of maximum registered daily new cases for each scenario was then calculated as:

$\alpha_{C}=\frac{\alpha_{D}}{L R}$

Where $\alpha_{C}$ is the maximum number of daily new deaths and $\alpha_{D}$ is the maximum number of daily new cases.

Brazil is still facing an exponential growth of daily new deaths and cases, what does not permit acceptable predictions on when the curve is going to bend. Figure 2 shows the plots of the number of daily new deaths and cases as a function of time, in days. Four scenarios are depicted based on the maximum number of daily new deaths, as described under Material and Methods. The forecast projections were done by using the Weibull distribution with the objective to predict the date of the peak maximum $\left(\tau_{0}\right)$, the total number of deaths and at the end of pandemic (area under the curve) and the modeled DDlag values. Each Panel shows predictions made from the number of daily new deaths (solid lines) and from the number of daily new cases (traced lines) select for each scenario. 
The analysis of the data fit within the Weibull distribution shown in Figure 2, it was possible to predict the numbers of daily new deaths at the forwarding days. As shown, if the number of the daily new deaths at the inflection of the curve increases the lasting of the peak tail would become longer, what would raise the death toll for COVID-19 in Brazil. Table 1 shows the modeled parameters for each one of the four predicted scenarios: number of daily new registered cases; overall death toll; modeled DDlag value; and estimated dates in which the number of daily new deaths and cases will be less than 626 deaths per day and 4,190 cases per day, respectively. These results supply data for supporting of discussion about the importance of the measures to be taken in order to properly fight COVID-19 outbreak. 


\section{Discussion}

COVID-19 is a global health emergency that is going to change the way in which people, institutions and governments manage their lives and duties. The fact that there is no known specific drugs or vaccines for COVID-19 until now raises the importance of behavioral strategies, such as social distancing, lockdowns [2-7] and mass testing $[8,19,20]$ in the fight against the pandemic. Our results show that the LR of COVID-19 in Brazil raised since the beginning of pandemic and reach a percentual value of $7.0 \pm 0.2 \%$. This value may be maintained constant until the end of the outbreak, as observed in other countries (data not shown). With this value, we were able to estimate the maximum number of daily new cases at the peak of the curve, and to model daily new cases curves for each scenario (Figure 2). For this, we multiplied the maximum number of daily new deaths in each considered scenario by the LR (0.07). Comparison analysis of daily new cases and deaths curves made it possible to estimate the DDlag value for each scenario (Table 1). DDlag has been shown to be an efficient, empiric parameter to evaluate the overall results of several governmental initiatives that affects the spread of COVID-19. DDlag displayed strong correlation with the lethality in some countries and can be used as a tool to evaluate the level of sub notification, as well as the efficacy of measures taken in response to the epidemic [14]. As shown in Table 1, modeled DDlag values were much higher than those observed on the curves displayed in Figure 2 for every scenario herein considered. Figure 2 displays that the observed DDlags - i. e., distances in days, between daily new cases and daily new deaths curves - are close to zero, inconsistently related to the values shown in Table 1. Such inconsistences, as well as values of DDlag close to zero, suggest a severe underreporting, overwhelming of health center, or even both, in Brazil [14].

As also shown in Table 1, the higher the number of daily new deaths, the longer it will last for Brazil to safely relax the stay-at-home measures. Our results suggest that, if the daily new deaths curve bends these days and starts to decrease (i. e. around 1,250 deaths per day), the number of daily new deaths in Brazil would fall under 629 at June, $18^{\text {th }} 2020$ (Table 1). As the maximum number of daily deaths impacts both the inflection of the curve and the lasting of the curve tail, our projections suggest that each additional day that Brazil takes to bend the daily new deaths curve adds more 3,718 deaths to the overall COVID-19 death counts in Brazil $\left(\mathrm{R}^{2}=\right.$ 0.9938). Because the forecast predictions on the number of daily new deaths were calculated based on each selected scenario (Figure 2, solid lines), while that one based on the number of daily new cases were estimated from LR (Figure 2, traced lines), we considered the first one more trustable than the last one. Predictions based on daily new cases and deaths are especially efficient because they can be daily revised, offering to governments and health authorities the opportunity of reconducting their measures as new data become available. We believe 
that such predictions can be used by decision makers in order to define strategies to fight COVID-19 both in the present days and in the future. These results depict the primal importance of reinforce the strict surveillance measures in Brazil, such as hardening lock-down measures, increasing the number of performed tests, improving the quality of health services and the work conditions of health professionals. These measures might be taken in order to flat the infections curve, i. e. the curves for daily new deaths and cases in view to mitigate the social and economic impact of COVID-19 outbreak in Brazil. 
References

1. Hopman J, Allegranzi B, Mehtar S (2020) Managing COVID-19 in Low- and Middle-Income Countries. JAMA. 323(16):1549 https://doi.dx.org/10.1001/jama.2020.4169.

2. Burki T (2020) COVID-19 in Latin America. Lancet Infect Dis. 20(5):547-8 https://doi.dx.org/10.1016/s1473-3099(20)30303-0.

3. Bong C-L, Brasher C, Chikumba E, McDougall R, Mellin-Olsen J, Enright A (2020) The COVID-19 Pandemic. Anesth Analg. https://doi.dx.org/10.1213/ane.0000000000004846.

4. IMF (2020) IMF Data [Internet]. World Economic Databases, April 2020. https://www.imf.org/external/pubs/ft/weo/2020/01/weodata/index.aspx. Accessed

5. Beltekian D, Ortiz-Ospina E (2018) Extreme poverty is falling: How is poverty changing for higher poverty lines? [Internet]. Our World in Data. https://ourworldindata.org/poverty-at-higher-poverty-lines. Accessed 2020 May 19

6. Roser M, Ritchie H, Ortiz-Ospina E, Hasel J (2020) Coronavirus Pandemic (COVID-19) [Internet]. https://ourworldindata.org/coronavirus. Accessed 2020 May 15

7. Bhatia S, Cori A, Parag K V, Mishra S, Cooper L V, Ainslie KEC, et al. (2020) Short-term forecasts of COVID-19 deaths in multiple countries [Internet]. Imperial College Lodon. https://mrcide.github.io/covid19-short-term-forecasts/index.html. Accessed 2020 May 23

8. Phillips D (2020) Brazil loses second health minister in less than a month as Covid-19 deaths rise [Internet]. The Guardian. Rio de Janeiro; https://www.theguardian.com/world/2020/may/15/brazilhealth-minister-nelson-teich-resigns. Accessed 2020 May 23

9. Londoño E, Andreoni A, Casado L (2020) Bolsonaro, Isolated and Defiant, Dismisses Coronavirus Threat to Brazil [Internet]. The New York Times. https://www.nytimes.com/2020/04/01/world/americas/brazil-bolsonaro-coronavirus.html. Accessed 2020 May 23

10. Ciufolini I, Paolozzi A (2020) Mathematical prediction of the time evolution of the COVID-19 pandemic in Italy by a Gauss error function and Monte Carlo simulations. Eur Phys J Plus. 135(4):355 
https://doi.dx.org/10.1140/epjp/s13360-020-00383-y.

11. Gupta S, Raghuwanshi GS, Chanda A (2020) Effect of weather on COVID-19 spread in the US: A prediction model for India in 2020. Sci Total Environ. 728:138860 https://doi.dx.org/10.1016/j.scitotenv.2020.138860.

12. Kim S, Seo Y Bin, Jung E (2020) Prediction of COVID-19 transmission dynamics using a mathematical model considering behavior changes. Epidemiol Health. 42:e2020026 https://doi.dx.org/10.4178/epih.e2020026.

13. Li L, Yang Z, Dang Z, Meng C, Huang J, Meng H, et al. (2020) Propagation analysis and prediction of the COVID-19. Infect Dis Model. 5:282-92 https://doi.dx.org/10.1016/j.idm.2020.03.002.

14. Moreau VH (2020) Projection of daily new cases and deaths of COVID-19 by Weibull distribution. Submited.

15. Lawless JF (2003) Basic Concepts and Models 1.1. In: Statistical Models and Methods for Lifetime Data, Second Edition. p. 1-47.

16. Khan SA (2018) Exponentiated Weibull regression for time-to-event data. Lifetime Data Anal. 24(2):328-54 https://doi.dx.org/10.1007/s10985-017-9394-3.

17. Toginho Filho, D. O.; Andrello AC (2009) Medição e propagação de erros [Internet]. Catálogo de Experimentos do Laboratório Integrado de Física Geral. Londrina, PR; http://www.leb.esalq.usp.br/leb/aulas/lce5702/medicao.pdf.

18. Remuzzi A, Remuzzi G (2020) COVID-19 and Italy: what next? Lancet. 395(10231):1225-8 https://doi.dx.org/10.1016/s0140-6736(20)30627-9.

19. Verma V, Vishwakarma RK, Verma A, Nath DC, Khan HTA (2020) Time-to-Death approach in revealing Chronicity and Severity of COVID-19 across the World. Navaneetham K, editor. PLoS One. 15(5):e0233074 https://doi.dx.org/10.1371/journal.pone.0233074.

20. Saez M, Tobias A, Varga D, Barceló MA (2020) Effectiveness of the measures to flatten the epidemic curve of COVID-19. The case of Spain. Sci Total Environ. 727:138761 https://doi.dx.org/10.1016/j.scitotenv.2020.138761.

21. Sjödin H, Wilder-Smith A, Osman S, Farooq Z, Rocklöv J (2020) Only strict quarantine measures can 
curb the coronavirus disease (COVID-19) outbreak in Italy, 2020. Eurosurveillance. 25(13):1-6 https://doi.dx.org/10.2807/1560-7917.es.2020.25.13.2000280.

22. Wilder-Smith A, Freedman DO (2020) Isolation, quarantine, social distancing and community containment: pivotal role for old-style public health measures in the novel coronavirus (2019-nCoV) outbreak. J Travel Med. 27(2):1-4 https://doi.dx.org/10.1093/jtm/taaa020.

23. Mitjà O, Arenas À, Rodó X, Tobias A, Brew J, Benlloch JM (2020) Experts' request to the Spanish Government: move Spain towards complete lockdown. Lancet. 395(10231):1193-4 https://doi.dx.org/10.1016/s0140-6736(20)30753-4.

24. Lau H, Khosrawipour V, Kocbach P, Mikolajczyk A, Schubert J, Bania J, et al. (2020) The positive impact of lockdown in Wuhan on containing the COVID-19 outbreak in China. J Travel Med. 27(3) https://doi.dx.org/10.1093/jtm/taaa037.

25. Anderson RM, Heesterbeek H, Klinkenberg D, Hollingsworth TD (2020) How will country-based mitigation measures influence the course of the COVID-19 epidemic? Lancet. 395(10228):931-4 https://doi.dx.org/10.1016/s0140-6736(20)30567-5.

26. Choi JY (2020) Covid-19 in South Korea. Postgr Med J. https://doi.dx.org/10.1136/postgradmedj-2020137738.

27. Salath M, Althaus CL, Neher R, Stringhini S, Hodcroft E, Fellay J, et al. (2020) COVID-19 epidemic in Switzerland: on the importance of testing, contact tracing and isolation. Swiss Med Wkly. 150(1112):4-6 https://doi.dx.org/10.4414/smw.2020.20225.

28. Peto J (2020) Covid-19 mass testing facilities could end the epidemic rapidly. BMJ. :m1163 https://doi.dx.org/10.1136/bmj.m1163. 


\section{Figures Captions}

Fig 1 Evolution of the lethality rate (LR) during the COVID-19 pandemic in Brazil

LR is given by the number of cumulative deaths divided by the number of cumulative cases. Points were fit within the Weibull equation for cumulative data. Dotted lines represent the $99 \%$ confidential intervals.

Fig 2 Weibull distribution on daily new cases and deaths as a function of time

Data on daily new cases (closed circles) and daily new deaths (open circles) were fit within the Weibull distribution (solid lines for deaths, traced line for cases). Four scenarios with distinct maximum rates at the peak top are shown (a) 1,250 deaths per day; (b) 1,500 deaths per day; (c) 1,750 deaths per day; and (d) 2,000 deaths per day. 
Table 1: Forecast projection parameters from modeled curves shown in Figure 2.

\begin{tabular}{cccccc}
\hline $\begin{array}{c}\text { Scenario } \\
\text { (deaths/day) }\end{array}$ & $\begin{array}{c}\text { Max. registered } \\
\text { cases / day }\end{array}$ & $\begin{array}{c}\text { Overall } \\
\text { Death toll }\end{array}$ & $\begin{array}{c}\text { Model DDlag } \\
\text { (days) }\end{array}$ & $\begin{array}{c}\text { Less than 626 } \\
\text { deaths/day }\end{array}$ & $\begin{array}{c}\text { Less than 4,190 } \\
\text { cases/day }^{\text {b }}\end{array}$ \\
\hline 1,250 & $17,934 \pm 3$ & $78,347 \pm 3,691$ & $13.7 \pm 0.7$ & July, $11^{\text {th }} \pm 6.4$ & June, $18^{\text {th }} \pm 4.7$ \\
1,500 & $21,521 \pm 3$ & $108,871 \pm 5,129$ & $19.0 \pm 1.2$ & July, 29 $9^{\text {th }} \pm 7.3$ & June, $24^{\text {th }} \pm 4.8$ \\
1,750 & $25,108 \pm 4$ & $141,731 \pm 6,684$ & $24.0 \pm 1.8$ & August, $14^{\text {th }} \pm 8.0$ & June, $29^{\text {th }} \pm 4.9$ \\
2,000 & $28,694 \pm 4$ & $176,757 \pm 8,336$ & $28.8 \pm 2.6$ & August, $29^{\text {th }} \pm 8,7$ & July, $19^{\text {th }} \pm 5.7$
\end{tabular}

a Errors propagated from standard errors and $\mathrm{R}^{2}$ and given by fit software.

b. Errors are presented in days. 


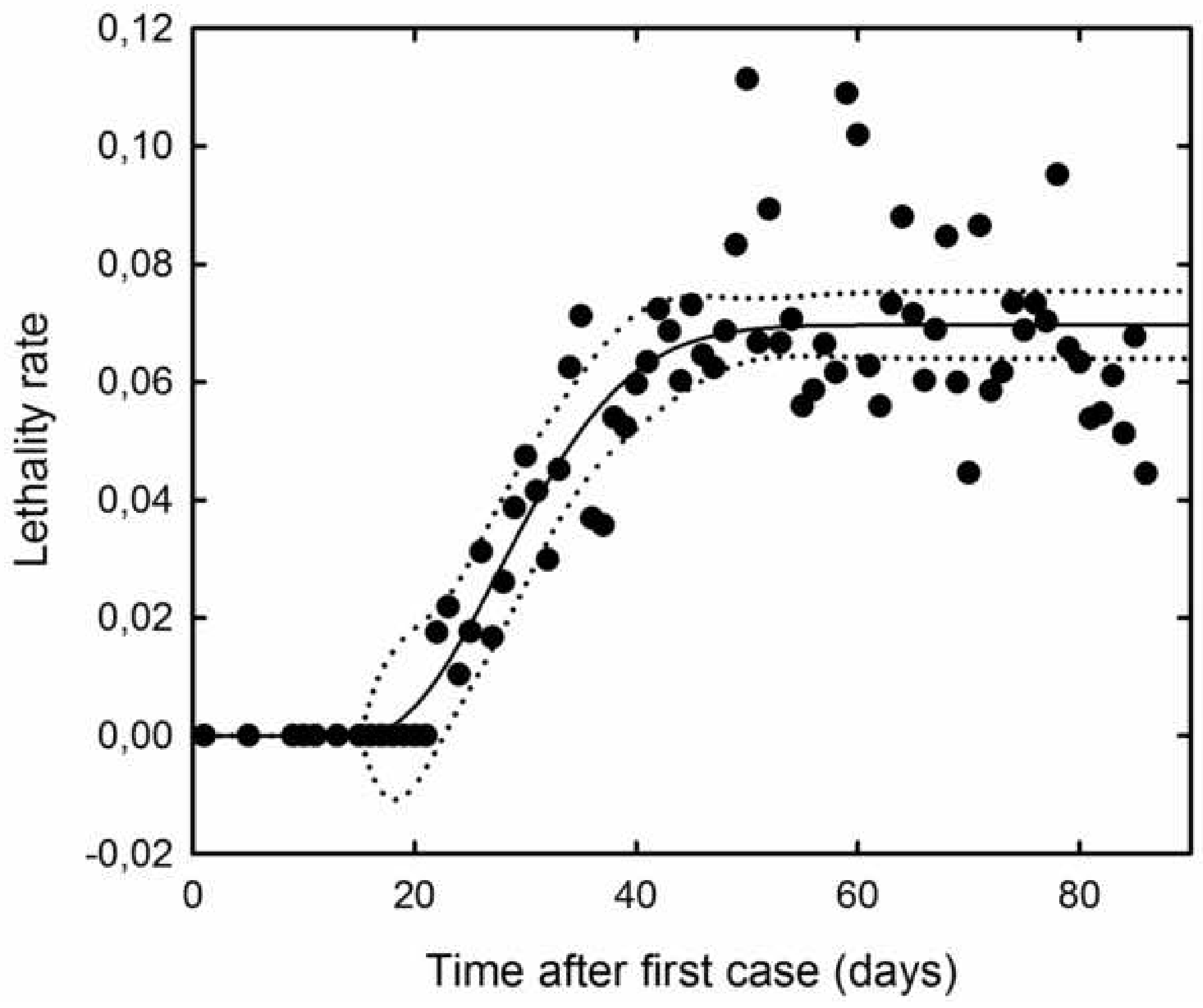




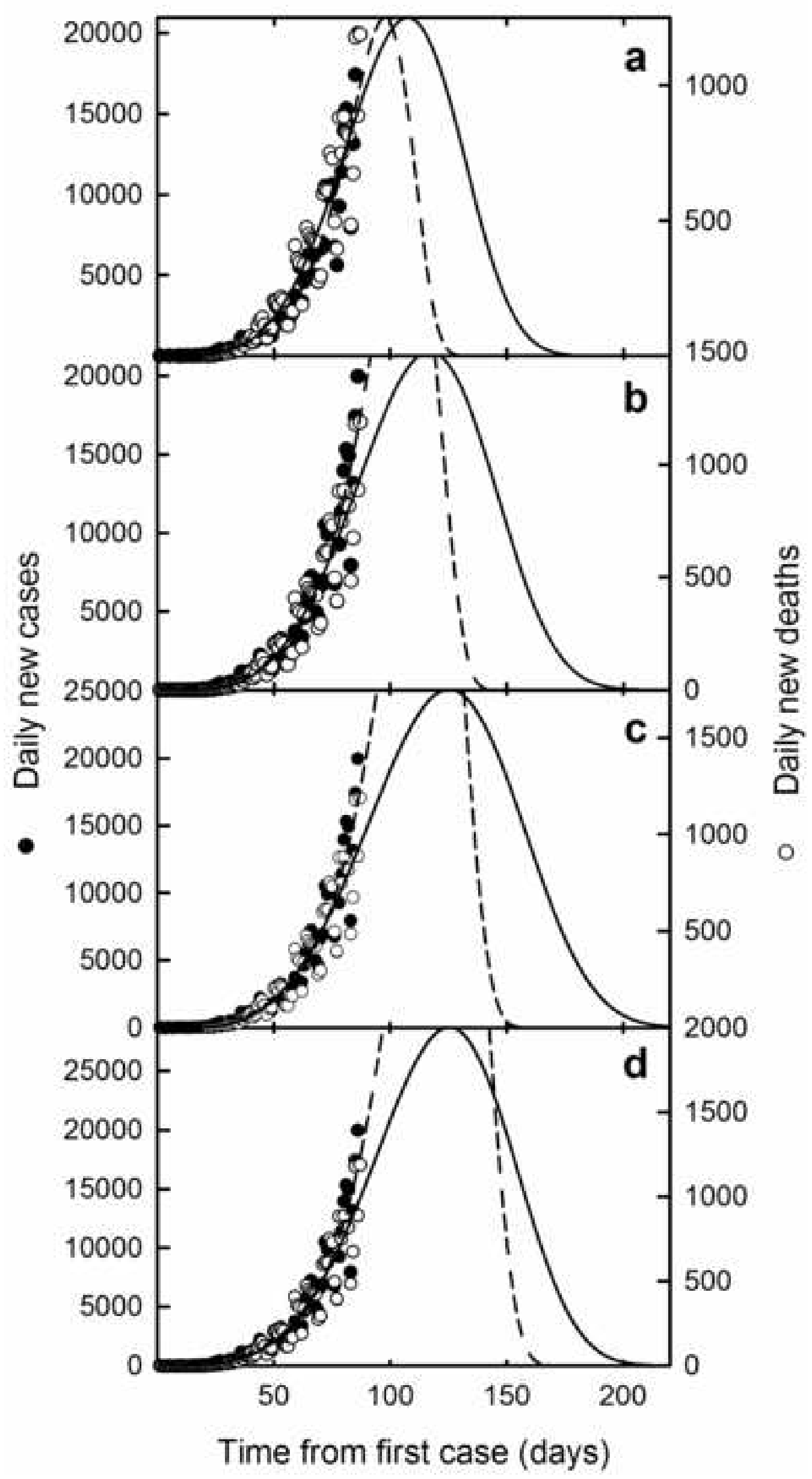


Figures

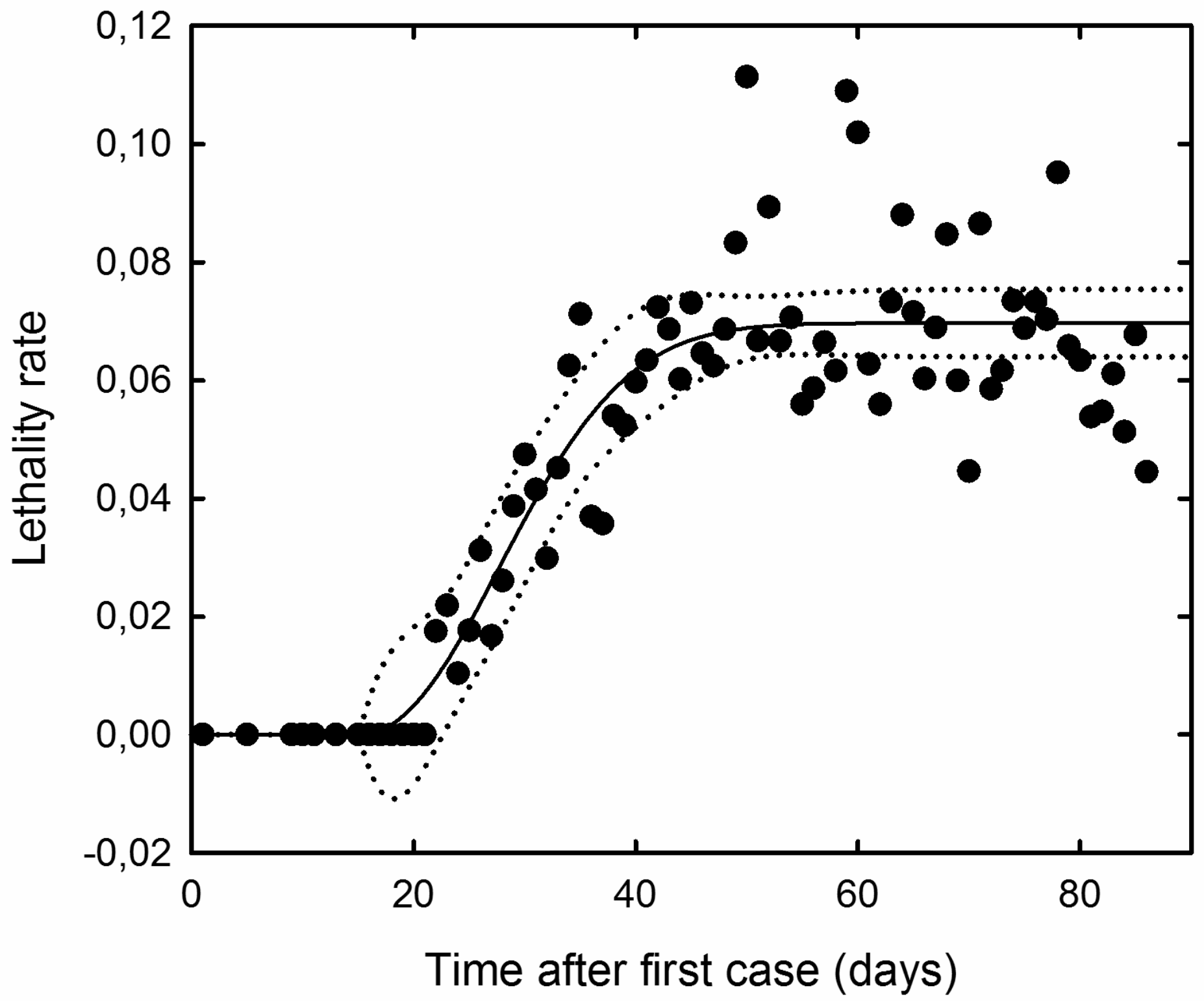

Figure 1

Evolution of the lethality rate (LR) during the COVID-19 pandemic in Brazil. LR is given by the number of cumulative deaths divided by the number of cumulative cases. Points were fit within the Weibull equation for cumulative data. Dotted lines represent the $99 \%$ confidential intervals. 


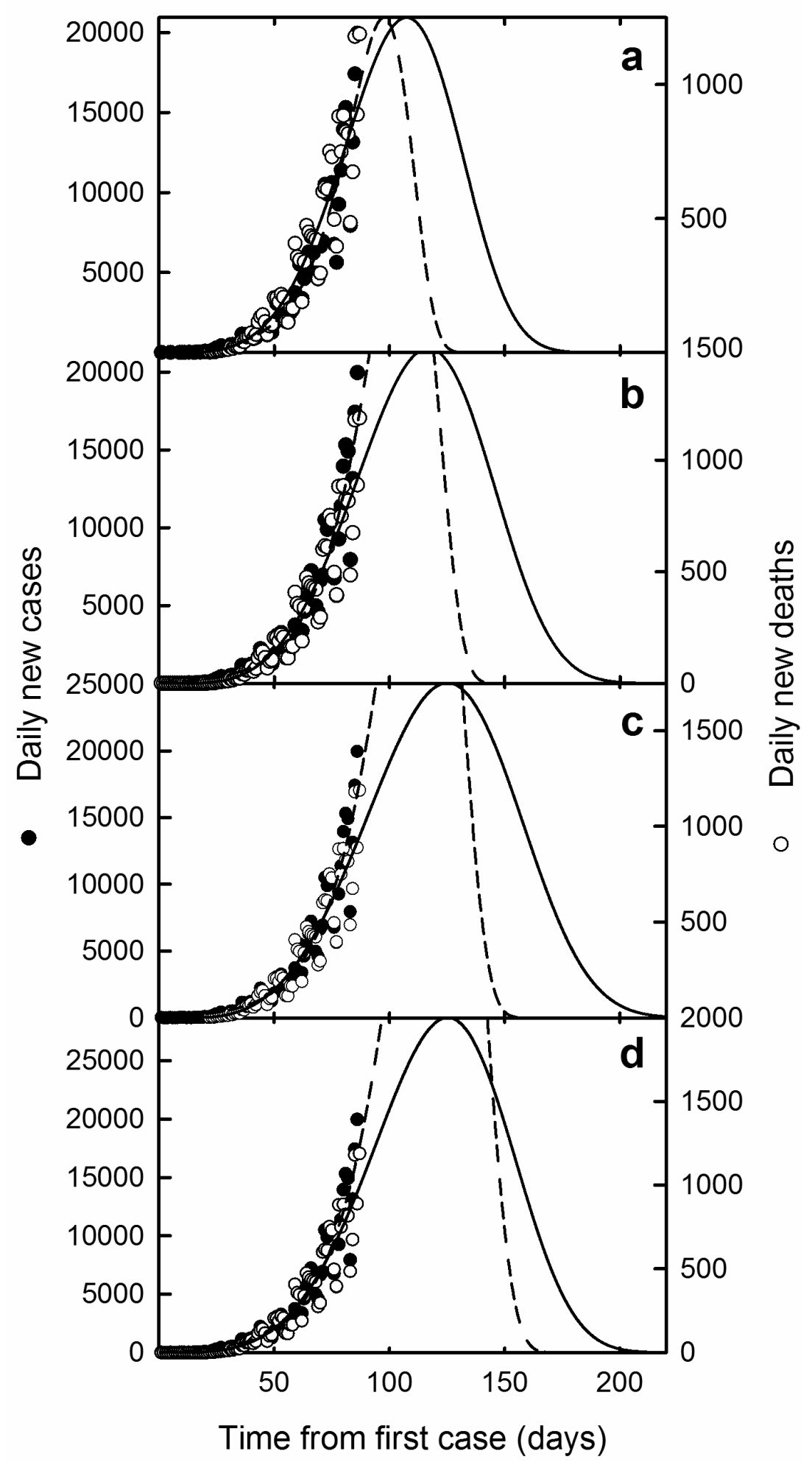

Figure 2

Weibull distribution on daily new cases and deaths as a function of time. Data on daily new cases (closed circles) and daily new deaths (open circles) were fit within the Weibull distribution (solid lines for deaths, traced line for cases). Four scenarios with distinct maximum rates at the peak top are shown (a) 1,250 deaths per day; (b) 1,500 deaths per day; (c) 1,750 deaths per day; and (d) 2,000 deaths per day. 